\title{
From Prison to Jail: Adapting to Teaching in a New Carceral Environment
}

\author{
Marc M. Howard, Georgetown University \\ Joshua A. Miller, Georgetown University
}

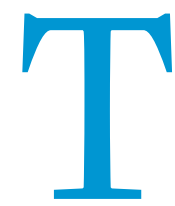

his article recounts our efforts, obstacles, struggles, and recent success in establishing a Georgetown University education program for incarcerated students. In the past year, under the auspices of Georgetown's Prisons and Justice Initiative, we launched the Georgetown Prison Scholars Program at the DC Jail (informally called the Scholars Program). The process is arduous and unpredictable at times, but we now appreciate the opportunity to work within a city jail-although we still hope to establish a prison-like situation in terms of continuity of incarcerated students. The key element to our recent breakthrough is a strong and committed partnership with the leadership of the District of Columbia's Department of Corrections (DC DOC).

Until recently, our experience with prison education took place in Maryland. Both authors had taught previously at the Jessup Correctional Institution (JCI), where for many years Miller ran the all-volunteer Prison Scholars Program, which had more than 160 students and offered an array of noncredit liberal arts courses in fall, spring, and summer semesters. After Miller developed a Second Chance Pell Grant program with the University of Baltimore in 2016, we learned in 2017 that the Scholars program would be abruptly canceled. This was despite its successful 20-year history, tremendous support from the incarcerated students, the fact that only a fraction of the number of students in the Scholars program could participate in the Baltimore program, and a full roster of courses scheduled for the following semester. Our requests for reconsideration, as well as numerous letters and grievances filed by JCI students, fell on deaf ears.

Soon thereafter, a different Maryland facility located near JCI-within a larger "web" of prisons in the Jessup areareached out to Howard and requested that Georgetown University start a credit-bearing prison-education program. By then, Miller had begun teaching philosophy at Georgetown and was assuming the role of Director of Education within the Prisons and Justice Initiative, which Howard founded in 2016. Although the space was less conducive to programming than at JCI, we visited the facility and had several meetings that seemed to be paving the way to a new partnership. Yet, once the discussions reached the state level, it became clear that Maryland simply did not want a new program in another facility-even in sites that do not currently host one.
Whether it was because Georgetown is not a Maryland institution or because Maryland administrators felt that the three existing credit-bearing programs offering courses to fewer than 200 of the state's 21,000 prisoners were sufficient-we eventually realized that we were not welcome under current conditions.

When one door closes, another opens-and, in this case, it happened in a rather unexpected way and place. We had engaged in tentative conversations with several DC DOC staff members, but we were initially skeptical that we could create a functioning program within a jail environment because-as Shanley explains in her article-jails present a host of challenges that make programming more complicated than in prisons. In early January 2018, after only a few meetings but much mutual goodwill and trust, we launched a pilot program for the spring semester-which began only two weeks laterwith seven not-for-credit courses. We were able to activate a roster of instructors from Georgetown to offer a class in philosophy, an English literature and composition workshop, and a lecture series by senior scholars, as well as a weekly training session offered by the Georgetown parliamentary debate team. We also offered two "inside-outside" courses, in music and "The Forgotten Humanity of Prisoners," in which Georgetown students worked side by side with DC Jail residents. Overall, after applying the same selection criteria used at JCI (i.e., GED, good-behavior record, resumé, and personal statement), our new program had 32 incarcerated students (26 men and six women) who could "commit" to being at the DC Jail from January through early May. Given the experimental nature of the program and our general skepticism about teaching in a jail, we kept our expectations low.

Yet, within only a few weeks, we knew that the semester was a rousing success. Despite the shorter-term nature of the facility, the students at the DC Jail were as talented and passionate as our students at JCI (many of whom had been incarcerated there for decades). We heard the same glowing assessments from faculty, visiting scholars, and outside students who visited the program. There also were challengesmost important, the fact that almost one third of our first cohort was released or transferred to federal custody during the semester. However, the experience was promising enough that halfway through the semester, we agreed with the DOC Director to offer a new set of courses in the summer semester 
and to start planning for credit-bearing courses that ultimately could lead to a college degree. For the summer session, we recruited 30 new students (in addition to many continuing students who remained in the program) and offered 12 courses on a variety of topics, including qualitative research methods, Moby Dick, and alternative dispute resolution. with Georgetown's School of Continuing Studies. In the Fall 2019 semester, we are offering two for-credit classes-one on "Introduction to Philosophy," the other called "Democracy," both taught by tenured Georgetown professors-to a cohort of 14 enrolled Scholars. We will offer several more in the spring and summer semesters as we expand our program.

\section{Our goal at the Georgetown Prison Scholars Program at the DC Jail is to create a prison education program inside a jail.}

The roots of our program stem from Georgetown University's deep commitment to Jesuit values and mission. Georgetown has a long tradition of volunteer teaching in correctional settings: numerous faculty members had taught at what was once the "DC prison" in Lorton, Virginia, before it closed in 2001. For more than three decades, a student-run Prison Outreach group has tutored incarcerated men and women at the local jails in Arlington and Alexandria, Virginia. However, the situation in Washington, DC, has become complicated since the closing of Lorton because DC residents who are sentenced to prison are treated as federal prisoners. Therefore, they serve their prison time within federal facilities run by the Bureau of Prisons, which means that they are sent all around the country. This is obviously problematic in terms of maintaining family and community ties, but it also prevents the establishment of a long-term program within a facility where the population is stable and continuous (as in all US states). The DC Jail is divided into the more "bare-bones" and dangerous Central Detention Facility (CDF) and the more programoriented Central Treatment Facility (CTF); the two sites are connected by a heavily guarded catwalk several floors above ground. As a result, the DC Jail is even more transitory than other local jails because the people who are transferred out typically scatter in all directions, often thousands of miles away.

Our goal at the Georgetown Prison Scholars Program is to create a prison education program inside a jail. We already knew that rigorous university education can thrive inside a prison. Moreover, after our experience in the spring and summer semesters, we know that it is still possible to offer high-quality, college-level education inside a facility that is predominantly transient and uncertain. Given DC's unique status and its ongoing struggle with the federal government over home rule, our project meshes well with the District legislature's desire to rebuild a prison infrastructure rather than sending its residents across the country to federal facilities, where they can communicate with family only via video visitation.

Our next step, therefore, is to establish a competitive, creditbearing, degree-granting program to which DC residents who are currently incarcerated in distant federal facilities can apply for admission. Successful candidates could return to the DC Jail for a much longer period-ideally, several years-perhaps even enough time to earn a degree.

We have recently made significant progress in that direction, by launching a credit-bearing program in partnership
At the same time, we are continuing to provide a full slate of non-credit courses and a distinguished Lecture Series to our 14 enrolled Scholars and an additional 36 incarcerated students, some of whom will themselves enroll for credit-bearing classes in the near future.

In the longer term, we also want to create a dedicated housing unit inside the DC Jail that can serve as a "learning community" or mini-campus, whereby program participants study together, receive additional tutoring and assistance, and flourish intellectually and academically. Our proposed program also would support assistance with reentry, mediation with family members, and preparation for job-readiness programs to facilitate what most returning citizens experience as a perilous transition. However, the realization of our vision depends on the cooperation of the DC DOC and especially the Federal Bureau of Prisons, which technically controls the fate of longer-term incarcerated DC citizens. Will it support the early return to the DC Jail of a cohort of federal prisoners who are dedicated to pursuing their education and highly motivated to succeed? We hope so.

Over the longer term, and with the right types of justicereinvestment initiatives, DC may decide to rebuild its own long-term incarceration program-a new prison. DC has the highest per capita incarceration rate of any state or territory in the United States, which means that there is ample room for a mixture of decarceral strategies and reentry support. We expect that Georgetown University's partnership with DC DOC will allow us to participate in co-creating those alternatives.

Although it may seem that our program and plans are unique to Washington, DC, we believe that some version of these goals could become the aim of many local jails and community corrections centers. A substantial body of evidence shows that state prisons-built in distant rural locations where land is cheap and the facilities are a major source of jobs-unduly damage family relationships and create too much distance between the professional educational and clinical staff best able to assist those incarcerated with reentry. Deemphasizing high-security facilities far from prisoners' homes in favor of community corrections must be a part of our country's overall response to mass incarceration.

It is worth emphasizing the importance of a supportive correctional administration: in Washington, DC, the relatively new DOC Director (Quincy Booth) hired a new Education Deputy (Amy Lopez), and the two of them set out to enact 
a new vision of DC Corrections. In addition, the CTF recently ended its contract with a private prison company, which led to a major reorganization. Not only did this transition accelerate staff turnover and provide an opportunity to remake the DC DOC culture, for the first time, it also made much of the shared programming space available to the Department
In light of overcrowding, rampant contraband and corruption, and general public indifference to the conditions under which American prisoners are incarcerated, corrections officials have full plates, and college programs can seem like a frustrating indulgence. Furthermore, the current generation of staff and administrators has spent an

\section{In light of overcrowding, rampant contraband and corruption, and general public indif- ference to the conditions under which American prisoners are incarcerated, corrections officials have full plates, and college programs can seem like a frustrating indulgence.}

of Corrections. Given the age of most prisons and the pressures of overcrowding, it is rare to find a facility with several unused classrooms. At JCI, adult basic education and GED teachers hoarded their spaces, teaching for four or five hours a day and refusing to allow their classroom to be used during the remaining time for religious services, drug treatment, or college classes. However, at the DC Jail CTF, we are now benefiting from an entire school's worth of previously unused classrooms that are hidden inside the facility's upper floors.

Despite our history of setbacks and challenges, Georgetown University's ongoing relationships with corrections departments in Washington, DC, Maryland, Virginia, and the Federal Bureau of Prisons provides unprecedented insight into four different correctional systems. Georgetown's research capacity allows us to intervene on issues connected to mass incarceration at multiple levels of policy, scholarship, programming, and advocacy. Our position in Washington, DC, also provides unique access to policy makers and the ability to shape legislative and regulative discussions. Our mission and commitment to social justice obligates us to use this access and ability to combat mass incarceration.

Correctional and academic aims sometimes seem to be at odds. Corrections staff and administrators are guided by custodial ethics: the requirement that they keep safe the people they incarcerate while preserving their basic liberties. entire career in correctional institutions unsupported by the Pell Grants that funded higher education in prisons until 1994. Despite the spate of press and academic articles, universities are still an unusual sight in prisons. However a new generation of correctional administrators and public officials is beginning to recognize that there is valuable overlap between academic and custodial aims: educational programming makes facilities safer, decreases recidivism, and restores the "rehabilitative" goals that we share. Supportive officials like those at DC DOC thus stand to reap the rewards of their values. Moreover, if the United States will restore Pell Grants for all prisoners rather than a small fraction-as some members of Congress have proposed in a bill called the REAL Act-then public officials must ensure that they are hiring and promoting correctional administrators who truly value education. This is important not only for achieving the shared goals of safety and security, but also because it positively transforms human beings, their families, their communities, and society overall. As DC DOC's leadership has shown, this can make all the difference.

Overall, Georgetown University's recent experience with the DC Jail demonstrates that a combination of goodwill and committed actors can establish a high-quality correctional educational program within a relatively short period-even inside a jail. 